\title{
Cod Removal Of An Industrial Effluent Using Nan crystalline Ceria Synthesized By Solution Combustion Method
}

\author{
A.A. Jahagirdar ${ }^{1}$, M.N. Zulfiqar Ahmed ${ }^{2}$, N. Donappa ${ }^{3}$, H. Nagabhushana ${ }^{4}$, \\ B.M. Nagabhushana ${ }^{5}$ \\ 1 department Of Chemistry, Dr. Ambedkar Institute Of Technology, Bangalore, India \\ ${ }^{2}$ Department Of Chemistry, Hkbk College Of Engineering, Bangalore, India \\ ${ }^{3}$ Department Of Chemistry, Maharani Lakshmi Ammanni College For Women, Bangalore, India \\ ${ }^{4}$ department Of P.G. Studies And Research In Physics, Tumkur University, Tumkur, India \\ ${ }^{5}$ Department Of Chemistry, M.S. Ramaiah Institute Of Technology, Bangalore, India
}

\begin{abstract}
Nanocrystalline ceria $\left(\mathrm{CeO}_{2}\right)$ was prepared by solution combustion method using cerium nitrate as oxidizer and citric acid as fuel. The as-formed $\mathrm{CeO}_{2}$ nanopowder was characterized by Powder X-ray diffraction, Fourier transform infrared spectroscopy (FTIR) and scanning electron microscopy (SEM). The nanoparticles were found to be agglomerated, fluffy and porous with a mean crystallite size of about $20 \mathrm{~nm}$. The as-formed ceria nanopowder was used for the removal of chemical oxygen demand (COD) of an industrial effluent. The effect of various factors such as $\mathrm{pH}$, dosage of nanopowder, stirring time and sedimentation time was studied. It was found that more than $89 \%$ removal of COD could be achieved at a pH of 4, for a catalyst dosage of $0.8 \mathrm{~g}$ of the nanopowder per liter of the industrial effluent with a sedimentation time of about 80 minutes.
\end{abstract}

Key Words: Ceria, Solution combustion, Scanning electron microscopy, Chemical oxygen demand.

\section{Introduction}

The development of modern industries over the last few decades has resulted in an an increase in the production of industrial wastewater containing large amounts of complex organic molecules which play a major role in environmental pollution. Accordingly, chemical, biochemical and solidification methods have been employed to treat industrial wastewaters. But these processes have some obvious drawbacks such as high costs and production of secondary pollutants. Therefore, development of an economical and convenient method for the treatment of industrial wastewater is necessary. It has been reported that nanoparticles exert good catalytic activities towards various chemicals. There are more than 3000 organic pollutants in water, which are difficult to be degraded by conventional methods. Many of these pollutants can be broken down by treatment with nanocrystalline metal oxides such as $\mathrm{TiO}_{2}, \mathrm{ZnO}$ etc. when induced by ultraviolet light [1-4]. This method is especially effective when it is used to treat effluents that contain high levels of organic pollutants that are not easily degraded by other processes. As a result it is believed that the application of nanotechnology and nanomaterials to water treatment will provide solutions to many environmental problems [5-7].

Waste water generated by different production steps of industrial effluents have wide range of $\mathrm{pH}$, detergents, oils, suspended and dissolved solids, toxic and non-biodegradable matter, color and alkalinity [8-9]. Nanocrystalline ceria is used in gas sensors, electrode material for solid oxide fuel cells and as catalyst for petroleum cracking. Several methods such as sol-gel, hydrothermal, co-precipitation etc. have been employed for the preparation of nanocrystalline ceria [10-13]. In the present study, nanocrystalline ceria was prepared by solution combustion method as this method is simple and the product is formed in a short period of time [14]. It was characterized by PXRD, FTIR and SEM. The as-formed nanocrystalline ceria was used for the COD removal of an industrial effluent. Results indicated that nanocrystalline ceria can be efficiently used for the COD removal from industrial effluents under UV light.

II.

2.1 Preparation of nanocrystalline ceria

Materials and Methods

All the chemicals were of analytical grade and were used without further purification. Distilled water used throughout the experiment. Cerium nitrate hexahydrate $\mathrm{Ce}\left(\mathrm{NO}_{3}\right)_{3} \cdot 6 \mathrm{H}_{2} \mathrm{O}$ was used as oxidizer and citric acid, $\mathrm{C}_{6} \mathrm{H}_{8} \mathrm{O}_{7}$ was used as fuel. A petridish of $300 \mathrm{ml}$ capacity containing an aqueous solution of the oxidizer and fuel was placed on a hot plate until the excess water was evaporated. It was then introduced into a muffle furnace maintained at $350^{\circ} \mathrm{C}$. It was observed that the reaction mixture first undergoes thermal dehydration and ignites instantaneously producing large amounts of gases. The flame temperature as measured by a thermocouple placed inside the muffle furnace and not touching the solution was found to be around $1200^{\circ} \mathrm{C}$. The combustion reaction was completed in just 10 minutes and finally nanocrystalline was formed as a light 
yellow and fluffy powder. Since the time taken for autoignition is very small, to remove the undecomposed nitrate, fuel and their decomposition products, the powder was calcined at $500^{\circ} \mathrm{C}$ for about 1 hour to obtain pure, well-crystallized powder.

\subsection{Characterization techniques}

The phase purity and crystal structure of the as-formed nanopowder was determined by PXRD with help of Scintag X-ray diffractometer using $\mathrm{Cu} K \alpha$ radiation $\left(\lambda=1.5418 \mathrm{~A}^{0}\right)$ with a nickel filter.

The various stretching and bending vibrations of the as-formed nanopowder were determined by FTIR. The FTIR spectrum was determined by using Perkin - Elmer spectrometer (spectrum 1000) with $\mathrm{KBr}$ as reference.

The surface morphology of the as-formed nanopowder was determined by SEM. The SEM micrograph was recorded using JEOL (JSM - 840A) scanning electron microscope.

\subsection{Determination of $\mathrm{COD}$ of the industrial effluent without $\mathrm{CeO}_{2}$ nanopowder}

The chemical oxygen demand value of the industrial effluent was determined by open reflux method number 5220B [15]. In case of sample titration, a known volume of the industrial effluent was mixed with acidified potassium dichromate solution. Calculated amounts of silver sulfate and mercuric sulfate were added and the mixture was refluxed at around $160^{\circ} \mathrm{C}$ for 2 hours. It was then cooled, diluted by adding $40 \mathrm{ml}$ of distilled water and the unreacted potassium dichromate solution was titrated against standard ferrous ammonium sulfate (FAS) solution using ferroin as indicator. A blank titration was carried out in a similar way except that in place of industrial effluent, same volume of distilled water was used. The COD value of the industrial effluent was calculated using Equation 1:

$$
C O D=\frac{8000 N(b-a)}{V} \ldots \ldots \ldots
$$

$\mathrm{N}=$ Normality of FAS solution

$\mathrm{b}=$ Volume of FAS solution consumed in case of blank titration

$\mathrm{a}=$ Volume of FAS solution consumed in case of sample titration

$\mathrm{V}=$ Volume of industrial effluent

\subsection{Determination of $\mathrm{COD}$ of the industrial effluent with $\mathrm{CeO}_{2}$ nanopowder}

A known volume of the industrial effluent was mixed with a known amount of the nanopowder and stirred magnetically under ultraviolet (UV) light for 30 minutes before proceeding for the COD determination. The degradable matter undergoes degradation by the $\mathrm{CeO}_{2}$ nanoparticles in the presence of UV light. The mixture was subjected to sedimentation. The supernatant liquid was carefully decanted and the COD was determined as described earlier. The COD removal was calculated using Equation 2:

$$
\% \text { COD removal }=\frac{100(p-Q)}{p} \ldots \ldots \ldots
$$

where, $\mathrm{P}=\mathrm{COD}$ of the industrial effluent without $\mathrm{CeO}_{2}$ nanopowder

$\mathrm{Q}=\mathrm{COD}$ of the industrial effluent with $\mathrm{CeO}_{2}$ nanopowder

\subsection{Effect of variables}

The effects of variable facors such as $\mathrm{pH}$, dosage of the nanopowder, irradiation time and sedimentation time were studied as follows:

The effect of $\mathrm{pH}$ on the COD removal was studied by conducting the experiment at various $\mathrm{pH}$ values ranging from $\mathrm{pH} 2$ to 12 . To study the effect of dosage of the nanopowder, the COD removal experiments were carried out by mixing the industrial effluent with various amounts of the nanopowder ranging from 0.2 to $1.2 \mathrm{~g}$ of the nanopowder per liter of the industrial effluent.

The effect of irradiation time was studied by exposing the mixture of industrial effluent and nanopowder for various time intervals ranging from 10 minutes to 60 minutes with intervals of 10 minutes. The effect of sedimentation time was determined after selecting the optimum dosage of the nanopowder. The sedimentation time was varied from the 10 minutes to 120 minutes with intervals of 10 minutes.

\subsection{Characterization techniques}

\section{Results and Discussions}

Fig. 1 shows the PXRD profile of the as-formed $\mathrm{CeO}_{2}$ nanopowder. All the peaks can be indexed to the pure cubic (fluorite) phase of $\mathrm{CeO}_{2}$. The lattice constants are comparable to the ones reported in literature for $\mathrm{CeO}_{2}$ (JCPDS 34-394). No impurity peaks were observed indicating pure phase of $\mathrm{CeO}_{2}$. The mean crystallite size of the nanoparticles was found to be about $20 \mathrm{~nm}$ as calculated by applying Scherer's formula (Equation 3) 
to the full width at half maximum (FWHM) of the intense peak at (111). The Scherer's formula can be written as

$$
\mathrm{D}=\frac{\mathrm{k} \lambda}{\beta \cos \theta} \ldots \ldots .
$$

where $\mathrm{D}$ is the crystallite size, $\lambda$ is the wavelength of $\mathrm{X}$-ray radiation $(0.15405 \mathrm{~nm}$ for $\mathrm{Cu} \mathrm{K} \alpha), \theta$ is the Bragg's angle and $\beta$ is the full width at half maximum of the most intense diffraction peak and $\mathrm{k}$ is an instrumental constant.

Fig. 2 shows the FTIR spectrum of the as-formed $\mathrm{CeO}_{2}$ nanopowder. The band at $3412 \mathrm{~cm}^{-1}$ can be ascribed to the $v(\mathrm{O}-\mathrm{H})$ mode of hydrogen bonded water molecules whereas the band at $1585 \mathrm{~cm}^{-1}$ is due $\delta$ $(\mathrm{OH})$. It has been reported that residual water and hydroxyl groups are usually detected in the as-prepared ceria samples irrespective of the method of synthesis employed. The peaks at 2361 and $1388 \mathrm{~cm}^{-1}$ arise due to the absorption of atmospheric $\mathrm{CO}_{2}$ on the metallic cation. The intense peak at $384 \mathrm{~cm}^{-1}$ is due to stretching frequency of the $\mathrm{Ce}-\mathrm{O}$ bond [16-18].

Fig. 3 shows the SEM micrograph of the as-formed $\mathrm{CeO}_{2}$ nanopowder. The particles have irregular shape with a wide distribution in size. A large number of voids can also be observed in the compound which can be attributed to the large amount of gases evolved during the combustion process. During combustion synthesis, the morphological characteristics of the nanoparticles are strongly dependent on the heat and gases generated during the reaction. Large volumes of gases help in formation of tiny particles whereas the heat released is an important factor in crystal growth. The particles are also agglomerated which is usually considered as a common way in which the nanoparticles minimize their surface energies.

\subsection{Effect of variables}

Fig. 4 shows the effect of $\mathrm{pH}$ on the COD removal. It can be seen that maximum COD removal occurs at a $\mathrm{pH}$ of 4 . Hence $\mathrm{pH} 4$ was considered as the optimum $\mathrm{pH}$. Fig. 5 shows the effect of amount of nanopowder on the rate of COD removal. From the figure it can be seen that maximum COD removal occurs for a dosage of $0.8 \mathrm{~g}$ of the nanopowder per liter of the industrial effluent. Hence the optimum dosage was considered as $0.8 \mathrm{gL}^{-}$ 1

Fig. 6 shows the effect of irradiation time on the rate of COD removal. It was found that maximum COD removal occurs for an irradiation time of 40 minutes. Hence optimum value of irradiation time was considered as 40 minutes.

Fig. 7 shows the effect of sedimentation time the rate of COD removal. It was found that maximum COD removal occurs for sedimentation time of 80 minutes. Hence optimum value of sedimentation time was considered as 80 minutes.

\section{Conclusions}

Nanocrystalline ceria was successfully prepared by solution combustion method. The characterization techniques reveal that the nanopowder is fluffy and porous with agglomeration of particles. A wide distribution in size of the particles was also observed and the mean crystallite size was calculated to be about $20 \mathrm{~nm}$. The results indicate that by selecting optimum values of $\mathrm{pH}$ at 4 , dosage of nanopowder at $0.8 \mathrm{gL}^{-1}$, irradiation tine at 40 minutes and sedimentation time at 80 minutes about $89 \%$ removal of COD of the industrial effluent can be achieved. It can be concluded that the variables such a $\mathrm{pH}$, dosage of nanoparticles, stirring time and sedimentation time have a greater influence on the rate of COD removal. By selecting optimum values of these variables, maximum COD removal can be achieved.

\section{Acknowledgements}

The authors appreciate the TEQIP Laboratory of M.S. Ramaiah Institute of Technology, Bangalore for providing the facilities used for the research work. AAJ acknowledges the Principal and management of Dr. AIT, Bangalore for the encouragement and support. MNZA is grateful to the Principal and management of HKBKCE, Bangalore for the encouragement and support. 


\section{References}

[1] M.R. Hoffmann, S.T. Martin, W. Choi and W. Bahnemann, Environmental Applications of Semiconductor Photocatalysis, Chem. Rev. 95 (1995) 69-96.

[2] Vidal A, Developments in Solar Photocatalysis for Water Purification, Chemosphere 36 (12) (1998) $2593-2606$.

[3] H.T. Gomes, J.L. Figueiredo and J.L Faria, Catalytic wet air oxidation of olive mill wastewater, Catalysis Today, 124(3-4) (2007) 254-259.

[4] A. Pela E. Tokat E, Color removal from cotton textile industry wastewater in an activated sludge system with various additives, Water Res. 36 (2002) 2920-2925.

[5] Zhiyan Guo, Fangfang Jian and Fanglin Du, A simple method to controlled synthesis of CeO ${ }_{2}$ hollowmicrospheres, Scripta Materialia,61 (2009) 48-51.

[6] Y.P Fu and C.H. Lin, Preparation of $\mathrm{Y}_{2} \mathrm{O}_{3}$-doped $\mathrm{CeO}_{2}$ nanopowder by microwave-induced combustion process, J. Alloys Compd., 389 (2005) 165-168.

[7] D.Y. Chung and E.H. Lee, Microwave-induced combustion synthesis of $\mathrm{Ce}_{1-\mathrm{x}} \mathrm{Sm}_{\mathrm{x}} \mathrm{O}_{2-\mathrm{x} / 2}$ powder and its characterization, $J$ Alloy Compd. 374 (2004) 69-73.

[8] Chyi-Ching Hwang, Ting-Han Huang, Jih-Sheng Tsai, Cheng-Shiung Lin and Cheng-Hsiung Peng,Combustion synthesis of nanocrystalline ceria $\left(\mathrm{CeO}_{2}\right)$ powders by a dry route, Materials Science and Engneering B: 132 (3) (2006) $229-238$.

[9] T. Wang and D. Cheng Sun, Preparation and characterization of nanometer-scale powders of ceria by electrochemical deposition method, Mat. Res. Bul. 43 (2008) 1754-1760.

[10] R.D. Purohit, B.P. Sharma, K.T. Pillai and A.K. Tyagi, Ultrafine ceria powders via glycine-nitratecombustion, Materials Research Bulletin 36 (2001) 2711-2721.

[11] YOU Jing, CHEN Feng, ZHAO Xiaobing and CHEN Zhigang, Preparation, characterization and catalytic oxidation property of $\mathrm{CeO}_{2} / \mathrm{Cu}^{2+}$ attapulgite (ATP) nanocomposites, J. Rare Earths, 28 (2010) 347-352.

[12] Qiang Yu, Xiaoxia Wu, Changin Tang, Lei Qi, Bin Liu, Fei Gao, Keqin Sun, Lin Dong and Yi Chen,Textural, structural, and morphological characterizations and catalytic activity of nanosized $\mathrm{CeO}_{2}-\mathrm{MO}_{\mathrm{x}}\left(\mathrm{M}=\mathrm{Mg}^{2+}, \mathrm{Al}^{3+}, \mathrm{Si}^{4+}\right)$ mixed oxides for $\mathrm{CO}$ oxidation, Journal of Colloid and Interface Science 354 (2011)341-352.

[13] Kingkaew Chayakul, Tipaporn Srithanratana and Sunantha Hengrasmee, Effect of $\mathrm{Re}$ addition on the activities of $\mathrm{Co}_{\mathrm{C}} \mathrm{CeO}$ catalysts for water gas shift Reaction, Journal of Molecular Catalysis A: Chemical 340 (2011) 39-47.

[14] J.J. Kingsley and K.C. Patil, A novel combustion process for the synthesis of fine particle $\alpha$-alumina and related oxide materials. Mater. Lett., 6 (1998), 427-432.

[15] Standard Methods for the Examination of Water and Wastewater. 19th edn, American Public Health Association/American Water Works Association/Water Environment Federation, Washington DC, USA(1995).

[16] M. Zawadzki, Preparation and characterization of ceria nanoparticles by microwave-assisted solvothermal process, J. Alloys Compd. 454 (2008) 347-351.

[17] T. Mokkelbost, I. Kaus, T. Grande and Einarsrud, Combustion synthesis and characterization of nanocrystalline CeO ${ }_{2}$-based Powders, Chem. Mater. 16 (2004)5489-5494.

[18] V. Bolis, G. Magnacca, G. Cerrato and C. Morterra, Microcalorimetric and IR-spectroscopic study of the room temperature adsorption of $\mathrm{CO}_{2}$ on pure and sulphated $\mathrm{t}-\mathrm{ZrO}_{2}$, Thermochimica Acta, 379(1) (2001) 147-161. 